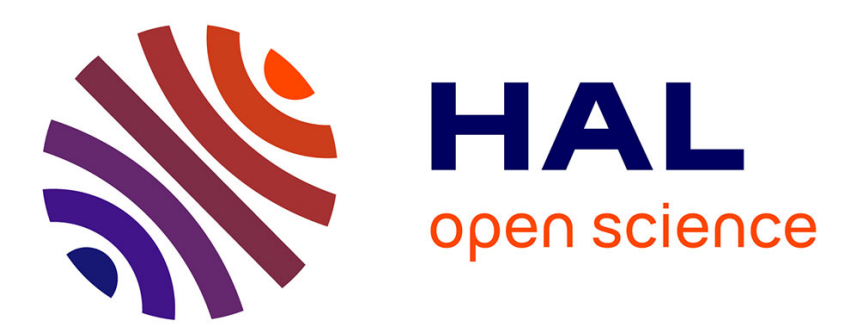

\title{
Hydrocarbon pyrolysis with a methane focus: A review on the catalytic effect and the coke production
}

\author{
Guillaume Fau, Nicolas Gascoin, Johan Steelant
}

\section{To cite this version:}

Guillaume Fau, Nicolas Gascoin, Johan Steelant. Hydrocarbon pyrolysis with a methane focus: A review on the catalytic effect and the coke production. Journal of Analytical and Applied Pyrolysis, 2014, 10.1016/j.jaap.2014.05.022 . hal-01253268

\section{HAL Id: hal-01253268 \\ https://hal.science/hal-01253268}

Submitted on 9 Jan 2016

HAL is a multi-disciplinary open access archive for the deposit and dissemination of scientific research documents, whether they are published or not. The documents may come from teaching and research institutions in France or abroad, or from public or private research centers.
L'archive ouverte pluridisciplinaire HAL, est destinée au dépôt et à la diffusion de documents scientifiques de niveau recherche, publiés ou non, émanant des établissements d'enseignement et de recherche français ou étrangers, des laboratoires publics ou privés. 


\title{
Hydrocarbon pyrolysis with a methane focus: a
}

\section{review on the catalytic effect and the coke production}

\author{
Guillaume Fau, ${ }^{*}, a$ Nicolas Gascoin, ${ }^{b}$ and Johan Steelant ${ }^{c}$
}

${ }^{\mathrm{a} U n i v e r s i t y ~ o f ~ O r l e a n s, ~ I N S A-C L V, ~} 88$ boulevard Lahitolle - 18000 Bourges, France.

${ }^{\mathrm{b}}$ INSA-CLV, 88 boulevard Lahitolle - 18000 Bourges, France.

${ }^{c}$ European Space Research and Technology Centre, Keplerlaan 1, 2201 AZ Noordwijk, The Netherlands

*Corresponding author: Tel.: +332482340 97. E-mail: guillaume.fau@univ-orleans.fr

\begin{abstract}
Hydrocarbon pyrolysis has been widely studied since the 1900 's for applications in aerospace as a fuel and/or coolant or for use with fuel cells and hydrogen production with a catalyst. In this context, the role of heterogeneous reactions with homogeneous phase chemistry is unclear despite the fact that it is obviously at the heart of coupled physico-chemical phenomena. In addition, the thermal formation of solid carbon particles -coke, which can be deposited on the structure, impacts the heterogeneous reactions. The aim of this work is to review the available literature on hydrocarbon pyrolysis involving reactions with solid surfaces and coke particles. The influent parameters such as the nature of the fluid, the temperature (up to $2000 \mathrm{~K}$ ), the pressure (up to 100 bars), the residence time ( $\mu$ s order to min order), the reactor type (plug flow, batch, perfectly stirred reactor) and the type of catalyst (inert, metallic or more complex such as zeolites) are discussed. Then, a link between catalicity and coke production is addressed. This literature survey focuses in particular on methane because of the growing interest regarding the potential for hypersonic applications.
\end{abstract}


21 Keywords: hydrocarbon pyrolysis, review, catalicity; coke production.

2.1 CATALYTIC EFFECT CONSIDERING A MASSIVE REACTOR......

2.1.1 Massive reactor: the intrinsic effect of the materials ............................................................................ 5

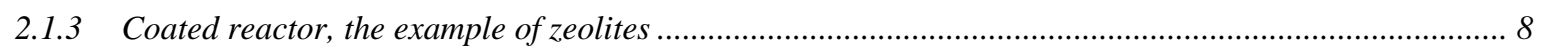

2.2.1 Unsupported metallic materials. 10

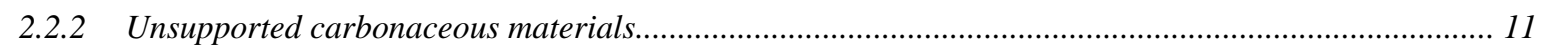

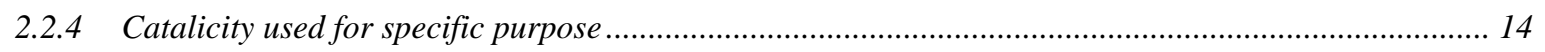

Within the scope of hydrocarbon pyrolysis, various parameters and conditions have been studied, 44 among which: the nature of the reactive fluid (methane [1], propane [2] and other even more complex 45 fluids, such as JP-7 [3]), temperature (from $400 \mathrm{~K}$ [4] to more than $2500 \mathrm{~K}$ [5]), pressure (from below 46 ambient pressure [6] up to $20 \mathrm{MPa}$ and even more [7]), type of reactor (shock tube [8], flow reactor [9], 
47 solar tube [10],), diluted [11] or pure [12] conditions. These experiments and the subsequent results

48 have enabled simple to complex kinetic mechanisms to be constructed in order to describe the chemistry

49 in detail and to perform numerical simulations in a multi-physics configuration. The numerous related works have progressively constituted an accumulation of results which are now diluted in the open literature. Only a few reviews are available and those for methane can be cited [13-15].

The surface catalytic effect, which is inherent to the reactor, is an additional complex phenomenon to be considered during hydrocarbon pyrolysis. A number of parameters (the nature of the catalyst, of the pyrolyzed fluid, several products, the ambient conditions, the ratio surface/volume $-\mathrm{S} / \mathrm{V}$, etc.) play a role and have been initially explored experimentally. From a numerical point of view, proposing kinetic schemes to describe heterogeneous reactions causes a rapid increase in the complexity of the models. Because heterogeneous reactions may be of importance, this justifies details and complex mechanisms being taken into account. Nevertheless, studies on the kinetics of reactions inherent in a large surface (i.e. the inner wall of the reactor) are quite rare. Rather than coating the inner surface of the reactor to study such catalytic effects, an alternative is to place a solid material, a catalyst, inside an inert reactor. Although the chemistry may be quite different, notably regarding the $\mathrm{S} / \mathrm{V}$, as suggested by Gordon [16], such data represent a precious source of information regarding heterogeneous chemistry.

In parallel, another critical phenomenon is the generation of solid particles. Pyrolysis leads to the carbon which can both dissolve in the fluid and condense on the reactor wall. Such particles can be classified according to several criteria. As an example, some studies distinguish coke according to its origin: pyrolytic [17], catalytic [18] or also asphaltic [19]. The production of such solid carbon depends on numerous parameters (temperature, pressure, residence, time, surface effect, oxygen content) and its formation has been widely studied in the literature, e.g. [20-22]. The particularity of solid carbon is that it can be deposited on the surface as a thin layer, and, in so doing, can, among other things, deactivate

71 the catalytic sites. Consequently, several studies have been conducted in order to avoid such deposits 72 thereby durably sustaining the activity of the catalysts (e.g. [23-25]). 
These two phenomena (catalicity and coke production) have generated a large number of data

74 disseminated over the years in the literature. The present paper aims at reviewing the articles related to

75 the catalytic effect and coke production during the thermal decomposition of hydrocarbons (mostly

76 small ones and notably methane). These two issues are linked in several ways: firstly, the catalytic

77 activity can, among other things, modifythe production of coke particles (in both ways: enhancement

78 and limitation). Secondly, coke can also have an impact on the catalicity of a material. Indeed, it can

79 stick to the surface of a material and in so doingdecrease or even inhibit its effect. The context of this

80 survey is that of regenerative cooling during hypersonic flights, i.e. the endothermic degradation of the

81 fuel which acts as a heat sink. Catalicity and coke production can be critical with respect to the cooling

82 method. Indeed, heterogeneous reactions could occur between the solid material and the fuel. The

83 interactions with the solid materials may either increase or decrease the fuel degradation and this has

84 both direct and indirect consequences on the internal convective cooling of the permeable solid material

85 by the fuel. The direct relationship is due to the pyrolysis rate. When the rate increases, the endothermic

86 effect is higher and the cooling efficiency is thus greater. The indirect relationship is that of the intrinsic

87 formation of coke (coke particles stick inside the pores of the solid material) which is higher for higher

88 pyrolysis rates. This coke layer decreases the heat transfer between the solid and the fluid. As a

89 consequence, cooling efficiency is lower in the case of coke formation. One can also notice that the

90 permeation process (fluid flow) is modified by the coke particles in case of clogging [26,27].

A wide review has been proposed of former works specifically concerning methane pyrolysis

92 [15]. This is expected to cover the field of catalicity and coking phenomenon to provide a complete

93 situation of hydrocarbon pyrolysis, particularly as applied to methane which is, as suggested by Davis et

94 al, a possible efficient fuel (advantageous standard enthalpy of combustion, low price, relatively low

95 coking rate) [28]. This study is mainly devoted to methane. However, it has been widened to include

96 several other hydrocarbons in order to provide complementary information when necessary. 
Even in the earliest methane pyrolysis investigations, it was observed that several parameters can modify both the kinetic and product ratio. Hurd and Pilgrim [29] pointed out that the species produced during the first instants of decomposition, the contact time, its relationship with the temperature and then, the surface reactor are all parameters to be taken into consideration. Slater [30] worked on the last point and clearly showed that each material has a specific effect on the decomposition rate. Therefore, in most cases, the surface effect was neither considered nor investigated but merely neglected. The catalyst effect may be considered in different ways, namely: the reactor material (metallic, composite), the treatment of the inner wall (e.g. coating) or by a small solid sample insertion. The following subsections investigate these techniques both in order to differentiate the results and to determine the consequences.

\subsection{Catalytic effect considering a massive reactor}

\subsubsection{Massive reactor: the intrinsic effect of the materials}

Studies on the catalytic effect of the inner wall of a reactor are relatively uncommon and were essentially conducted in the 1970 's. Before this, few researchers worked on this phenomenon. Thus, Hurd and Pilgrim [29] concluded that the nature of the reactor alters hydrocarbon pyrolysis. They

112 investigated the thermal degradation of butane in a reactor made of iron, nickel or monel (Ni-Cu-Fe 113 alloy) and they noted significant differences with high catalicity for a monel reactor. In comparison, 114 Hurd and Eilers also explored olefin pyrolysis in different metallic reactors and confirmed the high 115 activity of the monel reactor [31]. Regarding iron or nickel, less catalicity was found (decomposition at 116 a lower temperature for the first and modification of the product distribution for the second).

117 Several researchers explored other materials considering different small hydrocarbons. In [32], in 118 propane, ethylene and propylene pyrolysis Crynes and Albright observed little activity for nickel and 119 stainless steel reactors while a non-negligible catalicity for low carbon steel reactors was demonstrated. 120 They also performed tests inside mixed reactors (respectively $30 \%$ and $70 \%$ length of low-carbon steel 
121 and stainless steel) and noticed that a higher activity of low-carbon steel could be observed only if this 122 material was spatially placed after the stainless steel part. Given such results, the authors suggested the 123 role of the surface in the initiation and termination for free radical chain reactions. They also suggested 124 that tubes of small size (i.e. with a high $\mathrm{S} / \mathrm{V}$ ratio) present enhanced catalytic activity and inherent 125 surface reactions compared with bigger tubes but this is counter-balanced by the nature of the fuel 126 which is considered during the experiment (ethane or propane). Ghaly and Crynes further explored 127 propylene pyrolysis considering more materials [33]. More details are given and notably the nature of 128 the catalicity of each material. There are certain contradictions compared with the previous results. 129 Thus, for the stainless steel reactor, the wall activity is expressed via a higher production of carbon. The 130 low-carbon steel and nickel reactors had a fairly similar profile and demonstrated an increase of activity 131 during the first stage of pyrolysis (coke and hydrogen yield increased) and then it fell and reached a 132 steady-state after one hour. Such a trend suggested a progressive deactivation of the surface by the of 133 solid carbon. Inconel and incoloy reactors showed less activity. Ghaly and Crynes concluded that the 134 wall activity was essentially due to the presence of iron which acts as a catalyst for carbon and hydrogen 135 production. However, the presence of chromium in some alloys inhibits its activity. Therefore, a surface 136 containing an active carbon layer which carries iron atoms (e.g. low-carbon steel) may show higher 137 activity. Concerning nickel, it is assumed that the active sites have a lower affinity with hydrocarbons 138 than iron. Finally, alloys containing both iron and nickel may consequently be less effective than pure 139 metal. Dunkleman and Albright worked on paraffin (ethane and propane) pyrolysis and compared 140 metallic and Vycor glass reactors [2,34]. Significant differences were found between metallic and Vycor 141 reactors but it clearly appeared that the surface reactions had less importance for propane pyrolysis in 142 comparison with ethane experiments. Globally, they noticed that the hydrogen amount and coke 143 formation were lower for Vycor reactors than for metallic ones. In the 2000's, the works of the PRISME 144 laboratory on the catalytic activity of massive reactors constituted recent and quite unique data [35-37]. 145 For example, in [37], dodecane pyrolysis was investigated in two different tubular reactors (stainless 146 steel and titanium). Greater pyrolysis activity was noted for the titanium reactor at the same temperature 
147 than for a stainless steel one. Indeed the yields of the major products (ethane, ethylene and propane)

148 were multiplied by a factor of 2 while the conversion rate increased from $40 \%$ to $60 \%$. Nevertheless, it

149 was strange to note that a higher coke deposit was found for the stainless steel tube.

150 These first results demonstrated the mix effect of the catalicity of a reactor. For the same material 151 with the same fluid, substantial differences could be found. Additionally, the catalicity does not only 152 consist in reducing the temperature of hydrocarbon pyrolysis but can also clearly influence certain 153 reaction pathways. Parameters such as time, type of reactor or $\mathrm{S} / \mathrm{V}$ ratio are of the utmost importance 154 with regard to the catalytic phenomenon.

\subsubsection{Treatment of the inner surface}

The treatment of the reactor surface also constituted part of the research investigations on catalicity. In [32], in several cases the reactor was pre-treated (oxygen, hydrogen sulfide, steam, sulfur, anhydrous hydrogen bromide and nitric oxide). Oxygen treatment appeared to drastically affect the product distribution and to be an efficient catalyst for ethylene, propylene and carbonaceous solids

(Figure 1).

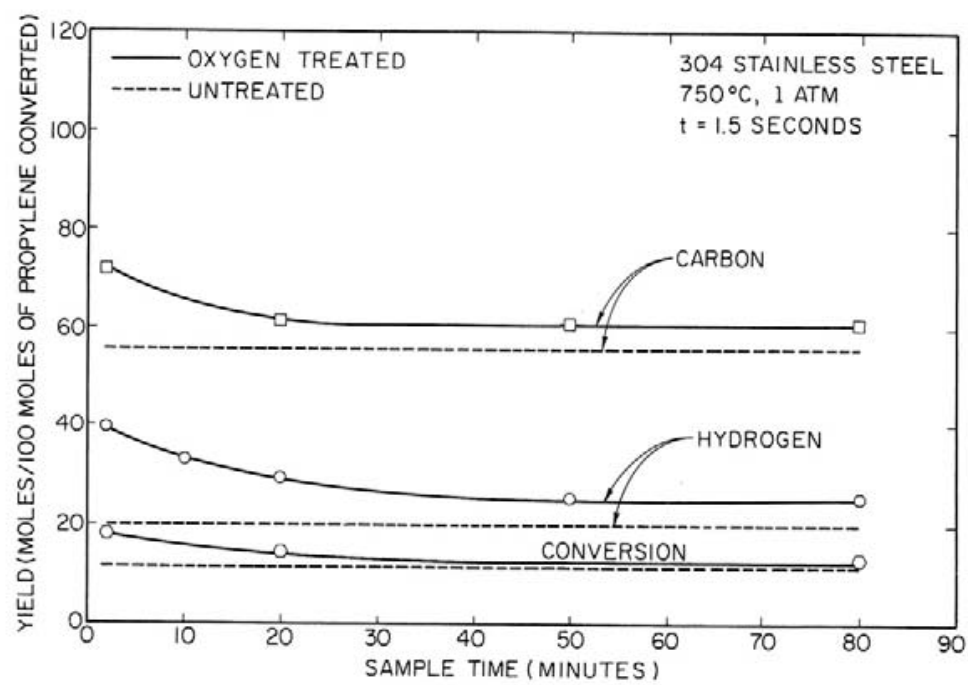

Figure 1. Effect of oxygen pre-treatment. From Crynes and Albright [32]

With regard to hydrogen treatment, it limited the activity while steam had a moderate influence 164 (the conversion increased from $32 \%$ to $35 \%$ ). Treatment with hydrogen sulfide inhibited the catalytic 
165 effect and was similar to a passivation (subsequent oxygen treatment is ineffective). Other treatments

166 did not significantly affect the hydrocarbon conversion. Ghaly and Crynes explored propylene

167 degradation and confirmed the higher activity for an oxygen pretreated stainless steel reactor but they

168 also noticed that such pretreatment moderated the activity of a low-carbon steel wall (oxygen acts a 169 protective oxide film) [33]. For nickel, this treatment presented no effect for the first 10 minutes before 170 undergoing a great increase due to the partial reduction of the oxide surface layer (by the action of the 171 carbon and hydrogen formed) which led to the formation of a more active nickel. For inconel and 172 incoloy, the results were close to those of oxygen-treated stainless steel. Finally, they found quite 173 different results regarding hydrogen sulfide pretreatment. Thus, a mixed effect was noted for stainless 174 steel (inhibition and then promotion) while a similar effect compared with oxygen was observed for 175 low-carbon steel (passivation). Dunkleman et al. confirmed the passivation effect of hydrogen treatment 176 on the degradation of small paraffin [2,34]. They explained such an effect by the reduction of the 177 surface reactions.

178 The pretreatment of a reactor has a clear impact on catalicity but such effects can clearly differ 179 depending on the materials treated and the treatment itself.

\subsubsection{Coated reactor, the example of zeolites}

Catalicity should be also studied by considering coated reactors. In this domain, several investigations have been conducted on particular materials such as zeolites or certain of its derivatives [38-41] but generally on heavy hydrocarbons. Zeolites have the great advantage of allowing fuel thermal degradation at lower temperatures whilst reducing the production of coke. The works of Li. et al. consisted in coating the inner wall of a stainless steel tube by a mixture of different zeolites (HZM-5) and a ceramic-like binder [38]. The pyrolysis of two jet fuels including dodecane was performed under supercritical conditions and within a continuous flow. They demonstrated that the heat sink capacity and conversion were enhanced by the zeolite coating with an increase of about $25 \%$ for the heat sink 
with Palladium inside the HZM-5 coating. Pd/HZSM -5 coating presented a better performance than HZSM-5 with a higher rate of conversion (increase of about $10 \%$ ) and a promotion of hydrogen yield (about twice as much). The heat sink was also enhanced, even more with the rise of the temperature. Meng et al. contributed to the zeolite coating studies by performing supercritical pyrolysis of ndodecane inside an HZSM-5 coated stainless steel reactor [40]. The authors observed that the conversion of dodecane was higher when the reactor was coated but only up to a certain temperature. Thus, for temperatures of over848 K, conversion becomes equivalent and even lower than for a nude reactor. This fact is explained by the progressive deactivation of catalytic sites by the filamentous coke. Liu and coworkers further investigated HZMS-5 zeolites under supercritical conditions [42]. They directed their study on the characterization of zeolites and highlighted the relative importance of the particle size. They found that coating a tube with nanoscale zeolites presented certain advantages and notably that of the enhancement of the catalytic activity (more than 1 time). Nevertheless, adhesion on the wall is poorer, but mixing nano- and microscale particles permits this problem to be overcome.

The catalicity of zeolite coated reactors is clearly demonstrated and shows interesting abilities namely regarding the reduction of the production of coke. Nevertheless, it must be mentioned that such catalysts are employed only at mid-range temperatures. Consequently, their application in the hottest parts of the cooling channel for jet fuel applications is not currently feasible since zeolites are not active in these conditions.

\subsection{Effect of small solid catalysts in a pyrolysis reactor}

Differentiation of the massive reactor experiments with the catalyst sample is namely motivated by the high importance of $\mathrm{S} / \mathrm{V}$ ratio or also the contact time with the catalyst. Hence, Gordon [16] was one of the first to experiment its impact on methane pyrolysis. He used a porcelain reactor whose catalytic activity is assumed to be very limited. However, it was demonstrated that this parameter clearly enhances methane decomposition. The pyrolysis rate was even multiplied by a factor of two to three (for an $\mathrm{S} / \mathrm{V}$ ratio multiplied by 3.5). Later, other research confirmed that this ratio was more or less 
215 critical for conversion and product distribution but that its importance was directly linked to the reactor

216 material $[2,32-34]$.

\section{$217 \quad$ 2.2.1 Unsupported metallic materials}

Chronologically, metallic catalysts were investigated first. These catalysts were inserted in reactor

219 considered to be inert (e.g. quartz). The term "unsupported" refers to this inactivity. Fang and Yeh [43]

220 considered 24 metal oxide catalysts deposited on a silica gel. Methane pyrolysis was performed at

$2211400 \mathrm{~K}$ and at $2.10^{-3} \mathrm{MPa}$ in a quartz reactor. The effectiveness of the metals was quantified with regard

222 to $\mathrm{C}_{2}$ selectivity and decomposition activity. They found that catalysts generally increase methane

223 decomposition but some of them can also decrease it with respect to quartz (e.g. $\mathrm{Bi}_{2} \mathrm{O}_{3} / \mathrm{SiO}_{2}$ ). Based on

224 their observations, they suggested a primary mechanism including the catalyst interaction. Van Der

225 Zwet et al. conducted a similar study in the presence of different aluminum oxides [44]. The effect of

226 the $\mathrm{S} / \mathrm{V}$ was confirmed and demonstrated a clear impact on product distribution. The increase in the $\mathrm{S} / \mathrm{V}$

227 leads to a progressive decrease in all the species excluding coke and tar (Figure 2).

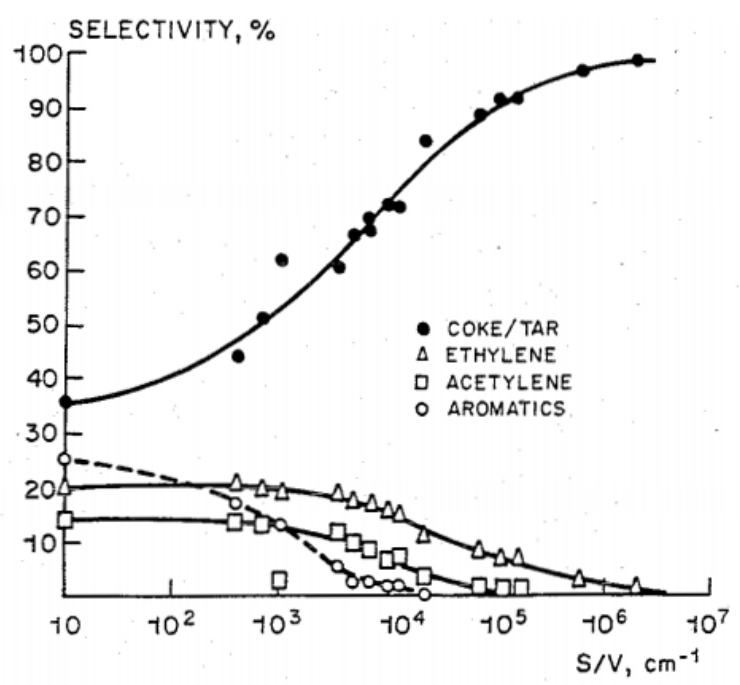

Figure 2. Selectivity to $\mathrm{C}_{2} \mathrm{H}_{4}, \mathrm{C}_{2} \mathrm{H}_{2}$, light aromatics and coke/tar as a function of surface to volume ratio at $25 \%$ conversion and $1398 \mathrm{~K}$ (reactor volume $\left.=10^{-6} \mathrm{~m}^{3}\right)$ [44].

232 explain such a fact, the authors assumed that the radical or dislocation sites of the surface may promote 
233 hydrogen abstraction. Moreover, due to the phenomenon of autocatalysis, it may have also an influence

234 on termination (by capturing from the gas phase the species involved in the autocatalysis). Finally, they 235 suggested that a large catalytic surface (aluminum oxide) is favorable to the production of coke and 236 hydrogen while gaseous and liquid products are preferentially produced in a reactor with a low $\mathrm{S} / \mathrm{V}$ 237 ratio. Wolf et al. [45] explored the effect of a platinum catalyst and modeled it over the temperature 238 range of $300 \mathrm{~K}-700 \mathrm{~K}$. Starting with the experimental results of Belgued et al. [46], they created a 239 mechanism composed of 39 elementary surface reactions involving 14 surface species. The kinetic 240 model accounts for the thin monolayer of carbonaceous overlayer which quickly covers the surface of 241 the catalyst. It includes successive steps from the reactant adsorption to the product desorption. Wolf et 242 al. pointed out that the dominance of a reaction on others depends on the contact time. They presented 243 Ethylidyne $\left(\mathrm{CCH}_{3}\right)$ as the determinant species of the mechanism, due to its surface decomposition to $\mathrm{C}$ 244 and $\mathrm{CH}_{3}$ and its influence on ethane production.

245 Zeolites have been also explored as small solid catalysts [e.g. 46-48]. Thus, Xian et al. worked on 246 the decomposition of dodecane over HZSM-5 under subcritical and supercritical conditions [48]. They 247 notably found that the activity of the catalyst decreases with the pressure increase and consequently 248 leads to a lower conversion. Such a trend opposes the other results found in the literature (e.g. Dardas 249 and coworkers [49]) and demonstrates, once again, the importance of the reactant and the 250 nature/properties of the catalyst.

\section{$251 \quad$ 2.2.2 Unsupported carbonaceous materials}

With regard to non-metallic catalysts, several studies have been performed using a carbon based catalyst. Hence, Muradov used different types of carbon [50,51]. He determined that graphite and carbon black showed the least activity whereas the initial methane decomposition rate was the highest in the presence of glassy carbon. Lee and coworkers investigated other carbon catalysts (coconut shell and coal) at $850 \mathrm{~K}$ [52]. Regarding the nature of the catalyst, they did not observe significant differencse in 
258 but is rapidly deactivated by the deposition of coke which blocks the pores. Pinilla et al.[53] tested two

259 activated carbons (carbon black) and found a similar trend i.e. high activity but limited as the process

260 progresses but they also noticed that the carbon produced by the degradation of methane can also show

261 a catalytic activity which slightly compensates for the deactivation. Bai et al. also explored the activity

262 of commercial activated carbon and compared it with alumina [54]. They observed less (due to the

263 higher activation energy) and different (autocatalytic reaction of carbon production) catalytic activity for

264 the metallic catalyst. They concluded that the methane conversion could be simplified by a two step

265 scheme withthe formation of carbon nuclei followed by growth in carbon crystallites. Moliner and

266 coworkers further investigated activated carbon and brought supplementary information about the main

267 characteristics which influence its activity [55]. They concluded that three elements have to be

268 considered: the surface chemistry, the size and the distribution of the pores, and the presence of

269 oxygenated compounds.

\section{$270 \quad$ 2.2.3 Supported materials}

It has been demonstrated that not only does the catalyst have an impact on chemistry but the support (i.e. the reactor) can also have a catalytic activity which leads to heterogeneous catalicity. The term "supported" refers to this phenomenon. Ferreira-Aparicio et al. specifically studied the interactions between $\mathrm{CH}_{4}$ and the surface of several catalysts [56]. They exposed the effect of different metallic catalysts (cobalt, nickel, ruthenium, rhodium, iridium and platinum) supported on alumina or silica, thereby demonstrating the importance of the support. Indeed, more hydrogen is produced by the catalysts supported on alumina than those on silica. Ruthenium and iridium were the least efficient catalysts for retaining carbon on their surface while the presence of rhodium on alumina support enhances the production of a more reactive coke (amorphous). Takenaka et al. further investigated the support effect on the nickel activity and on its catalytic lifetime [57]. It was observed that $\mathrm{SiO}_{2}, \mathrm{TiO}_{2}$ and graphite supports enhanced methane conversion. $\mathrm{Al}_{2} \mathrm{O}_{3}$ and $\mathrm{MgO}$ had the shortest lifetime. In 
differences namely regarding the size and the thickness of the carbon filaments. However, Zein et al.

284 [58] found quite different results. They investigated the catalytic decomposition of methane and the 285 subsequent production of $\mathrm{H}_{2}$ and of carbon. Nickel was chosen as the catalyst and $\mathrm{TiO}_{2}, \mathrm{Al}_{2} \mathrm{O}_{3}, \mathrm{MgO}$ 286 and $\mathrm{SiO}_{2}$ were selected as the support. The catalysis was performed at atmospheric pressure and for a temperature range of $823 \mathrm{~K}-1173 \mathrm{~K}$. Methane was mixed with argon $(1: 1$ mole $)$ and injected in a stainless steel reactor where $1 \mathrm{~g}$ of the catalyst was placed in its center. They concluded that titanium oxides were the best support (activity maintained after 2 hours) followed by $\mathrm{MgO}$. The $\mathrm{SiO}_{2}$ and moreover, the $\mathrm{Al}_{2} \mathrm{O}_{3}$ supports had the shortest lifetime. Finally, they proposed a mechanism similar to the preceding one with regard to carbon and $\mathrm{H}_{2}$ production:

$$
\begin{aligned}
& \mathrm{CH}_{4}+\mathrm{S} \leftrightarrow \mathrm{CH}_{4}-\mathrm{S} \\
& \mathrm{CH}_{4}-\mathrm{S}+\mathrm{S} \leftrightarrow \mathrm{CH}_{3}-\mathrm{S}+\mathrm{H}-\mathrm{S} \\
& \mathrm{CH}_{3}-\mathrm{S}+\mathrm{S} \leftrightarrow \mathrm{CH}_{2}-\mathrm{S}+\mathrm{H}-\mathrm{S} \\
& \mathrm{CH}_{2}-\mathrm{S}+\mathrm{S} \leftrightarrow \mathrm{CH}-\mathrm{S}+\mathrm{H}-\mathrm{S} \\
& \mathrm{CH}-\mathrm{S}+\mathrm{S} \leftrightarrow \mathrm{C}-\mathrm{S}+\mathrm{H}-\mathrm{S} \\
& \mathrm{C}-\mathrm{S}+\mathrm{S} \leftrightarrow \mathrm{C}+\mathrm{S} \\
& 2 \mathrm{H}-\mathrm{S}+\mathrm{S} \leftrightarrow \mathrm{H}_{2}+2 \mathrm{~S}
\end{aligned}
$$

Zadeh and Smith studied the pyrolysis of methane in presence of supported cobalt catalysts (Co$\mathrm{SiO}_{2}, \mathrm{~K}-\mathrm{Co}-\mathrm{SiO}_{2}, \mathrm{Co}-\mathrm{Al}_{2} \mathrm{O}_{3}$ and $\mathrm{K}-\mathrm{Co}-\mathrm{Al}_{2} \mathrm{O}_{3}$ ) [59]. A mixture of $\mathrm{CH}_{4}$ and $\mathrm{Ar}$ (respectively $95 \%$ and $5 \%$ ) was injected in quartz fixed-bed microreactor heated at $723 \mathrm{~K}$. They observed the so-called Metal Support Interaction (MSI) which consists in the migration of the $\mathrm{SiO}_{2}$ support onto the cobalt catalyst. The MSI increases the methane decomposition activity and the facilitation of the migration of carbonaceous species from the catalyst surface to the support. This phenomenon was promoted by the decrease of the initial Co loading. The temperature increase promoted the $\mathrm{CH}_{4}$ conversion and the metal coverage. As was mentioned in the previous part, the support also has an effect: conversion is greater for an alumina support than for a silica support. Finally, the addition of potassium was noticed to 308 promote the species migration from the metal to the support. 
Numerous studies have also been conducted on zeolite supported catalysts. Several combinations

310 with different metals have been tested. $\mathrm{Xu}$ and Lin have produced a very complete and interesting

311 review on this subject [60]. Globally, it appears that the molybdenum supported on HZSM-5 zeolite

312 presents the best association. Hence, further investigations have been conducted on this combination

313 and by modifying the catalyst preparation. Hence, for example, the works of Solymosi et al. who

314 explored methane degradation with unsupported and supported (notably zeolites ZSM-5) molybdenum

315 compounds can be cited [61-63]. According to the nature of the catalyst,its production method, and the

316 nature of the support, substantial differences were observed regarding the pyrolyzed products. The

317 authors also confirmed the progressive deactivation of the catalyst due to the carbon deposition.

\section{$318 \quad$ 2.2.4 Catalicity used for specific purposes}

Numerous works on the decomposition of methane with metallic catalysts have been conducted over the past years, but with specific goals. The production of $\mathrm{CO}_{2}$-free hydrogen is possibly the most important one $[64,65]$. The works of Shah et al. could be cited as an example [66]. They pyrolyzed methane and other different pure and binary metallic catalysts (Fe, $\mathrm{Pd}, \mathrm{Mo}, \mathrm{Ni}$ ) supported on alumina at

a temperature ranging from $673 \mathrm{~K}$ to $1173 \mathrm{~K}$. They pointed out the importance of the pretreatment of such materials: for example, methane is decomposed at a temperature of above $1123 \mathrm{~K}$ for a non-treated iron catalyst while the degradation begins 200 degrees lower after oxidization and even lower (723 K) if the catalyst has been previously reduced in a flow of hydrogen and then carburized. They also demonstrated that a binary catalyst (Fe-Mo, Fe-Pd, or Fe-Ni) always possesses higher activity (i.e. production of hydrogen) than a pure one. The production of carbon (e.g. filament) is also a widely studied topic. By way of example, González et al. explored the formation of carbon nanotubes using unsupported nanoparticles of nickel as a catalyst [67]. In such studies, the temperature is quite low and the aim is to obtain a fairly low conversion of methane coupled with a moderate carbon growth dynamic in order not to deactivate the catalyst. They tested the adjunction of copper in order to enhance the 
334 supported nickel catalysts. The third objective is the production of higher (i.e. heavier) hydrocarbons 335 like aromatics.

336 Thus, Holmen proposes an interesting overview of the research conducted in this domain [65]. He 337 points out that the zeolites associated with metals (preferentially molybdenum) are good catalysts and 338 initially enable acetylene and then aromatic compounds (notably benzene) to be formed. All in all, if the 339 interest of such works is undeniable, their purpose is quite far from the present one. For this reason, we 340 do not further review the numerous publications available in the open literature. A very valuable 341 literature survey of Amin et al.[68] is helpful to get a better view on the works which are devoted to the 342 three specific objectives mentioned above. The works of Ahmed and coworkers or Abbas and Wan 343 Daud also represent an abundant source of information in this domain $[69,70]$.

\section{3. Investigation on the coke deposits}

During the final steps of the pyrolysis of hydrocarbons, solid particles with high carbon content are produced. The so-called "coke" can be deposited on the inner wall of the reactor and it can be found under various natures; Albright et al. described seven different types of coke [71]. Thus, the term "coke" reassembles several different particles, which could lead to some confusion. Consequently, in this paper the definition proposed by Fitzer et al. [72] shall be employed. Coke is defined as a solid with a high content of the carbon element which is structurally in the non-graphitic state. Hereafter, the terms "coke" and "solid carbon" should be considered as equivalent.

Considering the hypersonic application considered in this work, knowledge of coke production is required since its deposit on the surface of the reactor wall has a critical impact on the decomposition of the fuel by changing the thermal equilibrium, modifying the surface catalytic effect and limiting the permeation and the associated cooling of the structure. Particularly, high pressure conditions (and even supercritical states) should be considered when dealing with coke formation. Unfortunately, no work dealing with coke production during supercritical methane pyrolysis was found. It can be noticed that 
358 other supercritical fluids have been explored in the open literature and the reader could refer to the

359 following reference for further information [21,73-75].

\subsection{Characterization of the coke particles and parameters of influence}

Determining the coke characteristics and the parameters which enhance or inhibit its production is important in overcoming the drawback of fuel pyrolysis when used aboard aerospace vehicles. According to the literature, several parameters of importance have a clear influence on coke production. Among them, can be cited: the residence time, the nature of the fluid, the pressure or also the geometry of the reactor [76-83].

Blekkan et al. [76] studied tar and coke formed during methane pyrolysis in a tubular reactor. First, they highlighted the critical role of acetylene, benzene and PAH formation. They distinguished two types of solid carbon particles: tars containing a high proportion of heavy PAH (e.g. pyrene), come from liquids and stick to the reactor wall, and soot, formed in the gas phase from reactive species like acetylene. They pointed out a first parameter of influence on coke production which is the residence time. It was observed that coke selectivity reaches about $80 \%$ for a residence time of 1 second while it is only $20 \%$ for $0.5 \mathrm{~s}$. Guéret et al. confirmed the role of residence time and added more details. But contrary to Blekkan et al., they distinguish three types of coke and also work on the temperature influence [77]. Globally, they classified the solid carbon deposit as follows: graphitic type which is produced whatever the residence time (it seems to act as an initial layer) and is predominant for temperatures of over $1423 \mathrm{~K}$; amorphous (carbon black) whose production increases with the residence time and is maximal between $873 \mathrm{~K}$ and $1423 \mathrm{~K}$; and soot which is produced for short residence times (lower than $0.6 \mathrm{~s}$ ) and at low temperatures $(573 \mathrm{~K}-873 \mathrm{~K})$. Albright and Marek confirmed the critical importance of the residence time (considering longer periods than the previous one), but also added two other parameters which are the geometrical features of the surface and the time of operation [78]. They pyrolyzed acetylene and toluene in a Vycor glass tubing reactor where two rectangular specimens were placed. The amount of solid carbon and the nature of the coke were different depending on the residence 
383 time, the length of the pyrolysis run, the position of the specimen and its nature. Regarding the coking 384 rate, two maxima could be reached for different residence times ( $3 \mathrm{~s}$ and then $9 \mathrm{~s})$. They assumed that 385 this signals the existence of two different mechanisms as a function of the production of certain 386 precursors. The morphology of the coke significantly varies with the residence time. Thus, spherical coke particles whose size increases with the residence time and filamentous carbon which is produced preferably for a second order residence time were observed. Geometrical factors, such as the way the specimen is inserted in the reactor or the $\mathrm{S} / \mathrm{V}$ ratio, play a significant role and this impacts the coke quantity, the particle size and the coking rate. In addition, the morphology changed significantly along with the progress of the coke production (increase of the diameters of both the spherical and filamentous coke). The nature of the specimen (incoloy, stainless steel, quartz, and vycor) also affected the coke production with a higher value for the metallic one. The authors suggested that heterogeneous reactions can enhance or limit the coke deposition and its nature. This will be discussed later. Finally, Albright and Marek [78] also observed that the length of the experiment can also modify the morphology of the carbon particles. This could signal a modification of the coking mechanism during the progress of the order: vycor glass, incoloy and then stainless steel. Additionally, it was observed that the $\mathrm{S} / \mathrm{V}$ ratio has an impact, i.e. the higher $\mathrm{S} / \mathrm{V}$, the larger the carbon deposit. A mechanistic model of 18 reactions was developed in complement to their experimental data. Due to the very limited results, the model did not integrate surface reactions but "suppressed" them by correcting the initial reaction rates of the "classical" reaction pathway and simulating a surfaceless experiment. Such a correction permitted good agreement to be obtained between numerical predictions and experimental results. Altin and Elser $[79,80,84]$ also explored the impact of the surface and compared the deposition of carbon, from JP-8 pyrolysis, on several surfaces and notably on two superalloys (Inconel 600 and Inconel X). The carbon deposition was 15 times higher for Inconel 600 than for Inconel X. Filamentous carbon coated by a carbonaceous layer remained on Inconel 600 while both crystalline and amorphous carbons were 
409 deposited on Inconel X. Such differences are explained by the presence of several elements (e.g. Ti or

$410 \mathrm{Al})$ which act as carbon deposit inhibitors. Gascoin et al. conducted similar investigations [20] by

411 performing dodecane pyrolysis experiments in stainless steel, low carbon steel and titanium tubular

412 reactors. They provided the characteristics of the coke produced thanks to SEM observations, EDS, X-

413 ray and FTIR analysis. The coke has different aspect as a function of reactor nature (e.g. for stainless

414 steel tube, millimetric aggregates constituted from micrometric particles were mainly formed inside the

415 fluid flow while for steel reactors, the deposit appeared as very dry sticky shavings). They found spatial

416 heterogeneous deposit along the reactor. The increase of the residence time or of the pressure enhances

417 the formation of coke while the production of solid carbon has been linked to methane formation. In

418 [81]. Reyniers et al. confirmed the role of pressure in the increase of the carbon productions. Lucas and

419 Marchand pyrolyzed methane in a tubular reactor while modifying the temperature, the pressure and the

420 flow rate [82]. They observed that the temperature and flow rate did not impact the density of the coke

421 particles, the increase of pressure led to a decrease in the density. Naturally, the studies mentioned 422 above are just a fraction of the numerous works which are available in the literature (e.g. studies on the 423 effect of the surface on coke production, Ref.[85-90]). As explained by Oberlin in her excellent review 424 [83], a considerable quantity of research has been performed under a very wide panel of conditions. This 425 is why the results are so mixed and, sometimes, contradictory. This is why the first part of this paper 426 aims at isolating the works which present the main information related to the influent parameters on 427 coke production. Thus, it has to be noted that the increase of the pressure, the temperature and the 428 residence time favor coke production. Regarding a hypersonic application, the first two parameters are 429 not easy to control efficiently. On the contrary, acting on the residence time in order to shorten it but 430 also using specific materials are parameters which appear, to a certain extent, more controllable.

\section{$431 \quad 3.2$ Modeling the coke formation and its coupled impact on surface deactivation}

Guéret et al. [77] studied the solid carbon production from the methane pyrolysis and they 433 proposed an extensive literature survey. Their conclusion was that coke formation begins with the 
434 formation of radicals from hydrocarbon degradation. Then, condensation and polymerization reactions 435 lead to the production of some "complexes" (intermediates molecules in the formation of coke). At this 436 point, there are two possibilities: on the one hand, adsorption of complexes at the surface and formation 437 of an anisotropic pyrolytic carbon layer or on the other, condensation and polymerization of these in the 438 gas phase. This last pathway is faster than the first one and generates a dispersed carbon with an 439 isotropic structure (the so-called carbon black). Lucas and Marchand supplied a first approach for 440 modeling the coking mechanism in case of methane pyrolysis [82]. They determined that $\mathrm{C}_{2}$ 441 hydrocarbons (acetylene and ethylene) and benzene were the most represented light species while 442 naphthalene, anthracene, phenanthrene, acenaphtylene, pyrene and fluoranthrene were found to be the 443 most common PAHs. Based on those results, Lucas and Marchand proposed the following simple 444 mechanism divided into 4 steps:

$$
\mathrm{CH}_{4} \underset{\text { STEP } 1}{\stackrel{\text { (Fast) }}{\longrightarrow}} \mathrm{C}_{2} \underset{\text { STEP } 2}{\longrightarrow} \mathrm{C}_{6} \mathrm{H}_{6} \underset{\text { STEP } 3}{\longrightarrow} \mathrm{PAH} \underset{\text { STEP } 4}{\longrightarrow} \text { Carbon }
$$

They noted that the $\mathrm{C}_{2}$ species had an essential role in the formation of benzene and of different 447 PAHs. Considering the kinetics of the reactions, they assumed that methane dissociation coefficient had 448 practically no influence on the production of $\mathrm{C}_{2}$ because of the rate of the first step. On the contrary, a 449 low dissociation coefficient of methane would decrease the formation of benzene and PAH while for a 450 higher one, the production of benzene and PAH would initally increase before diminishing. The authors 451 observed that carbon was more actively produced by reactions involving anthracene than the other 452 PAHs. This simple mechanism was used and extended by Benzinger et al. [91]. They divided the coking 453 phenomenon into five steps beginning with the cracking of methane:

454 STEP 1: From to methane to ethane:

$$
\mathrm{CH}_{4} \longrightarrow \mathrm{CH}_{3}+\mathrm{H}
$$

$$
\mathrm{CH}_{3}+\mathrm{CH}_{4} \longrightarrow \mathrm{C}_{2} \mathrm{H}_{6}+\mathrm{H}
$$

$$
2 \mathrm{CH}_{4} \longrightarrow \mathrm{C}_{2} \mathrm{H}_{6}+\mathrm{H}_{2}
$$

STEP 2: From ethane to ethylene: 


$$
\mathrm{C}_{2} \mathrm{H}_{6} \longrightarrow \mathrm{C}_{2} \mathrm{H}_{4}+\mathrm{H}_{2}
$$

$$
\mathrm{CH}_{3}+\mathrm{C}_{2} \mathrm{H}_{6} \longrightarrow \mathrm{CH}_{4}+\mathrm{C}_{2} \mathrm{H}_{5}
$$

$$
\mathrm{C}_{2} \mathrm{H}_{5}+\mathrm{H} \longrightarrow \mathrm{C}_{2} \mathrm{H}_{4}+\mathrm{H}
$$

STEP 3: From ethylene to acetylene:

STEP 4: From acetylene to benzene:

$$
3 \mathrm{C}_{2} \mathrm{H}_{2} \longrightarrow \mathrm{C}_{6} \mathrm{H}_{6}
$$

STEP 5: Growth of solid carbon $\left(\mathrm{C}_{\infty}\right)$ :

$$
\mathrm{C}_{\infty}+\mathrm{C}_{6} \mathrm{H}_{6} \longrightarrow \mathrm{C}_{\infty}+3 \mathrm{H}_{2}
$$

So, methane first cracks into $\mathrm{C}_{2}$ hydrocarbons. The condensation of acetylene leads to benzene and finally to the growth of carbon particles. Even if other compounds contribute to the coking phenomenon, benzene remains the most important intermediate species. Becker and Hüttinger followed their investigations on coking and performed experiments [92]. The authors observed the following elements. First, they found that the $\mathrm{C}_{1}$-species can form coke directly. Secondly, the deposit rate shows an exponential increase with residence time. Thirdly, the increase of the initial partial pressure leads to the raise of $\mathrm{C}_{1}$ to $\mathrm{C}_{6}$ species with a plateau for ethane, ethylene and acetylene. Finally, hydrogen decreases coke production by saturating the free radical active sites. This leads to a critical fall of acetylene and of benzene formation. Based on those elements, the authors proposed a basic coke formation scheme where coke can be directly formed from numerous hydrocarbons including methane itself. It was also demonstrated that ethylene is not only formed from ethane, acetylene not only from ethylene and benzene not only from acetylene. These last assertions clearly reveal that a realistic coking mechanism involves a high number of reactions. Albright and Marek proposed a relatively more 
complex model [93]. They combined three distinct -but linked- mechanisms. The first one (the so-called mechanism 1) considers the catalytic effect of the reactor and involves metal-catalyzed reactions. The coke produced by such a mechanism is filamentous and often contains metal. Acetylene is a predominant precursor while metal carbides are considered as intermediate compounds and iron and nickel as catalysts. Such coke is produced at temperatures ranging from $673 \mathrm{~K}$ to $1323 \mathrm{~K}$. Mechanism number 2 highlights the importance of aromatics species (Ar-H) as intermediate in the formation of coke. A majority of those compounds come from acetylene. The following schematic sequence describes the production of solid carbon:

$$
n \mathrm{Ar}-\mathrm{H} \stackrel{-\mathrm{H}_{2}}{\longrightarrow} \text { tars } \underset{\text { condensation }}{\stackrel{\text { nucleation }}{\longrightarrow}} \text { tar droplets } \stackrel{-\mathrm{H}_{2}}{\longrightarrow} \text { semitar droplets } \stackrel{-\mathrm{H}_{2}}{\longrightarrow} \text { coke }
$$

This coke is metal-free and does not appear below $973 \mathrm{~K}$. The last mechanism describes the growth of the coke layer involving microspecies (generally acetylene) with the free radicals (methyl, ethyl, phenyl or benzyl radicals) on the coke surface forming aromatic rings. Hence, the authors concluded that acetylene is essential in the production of solid carbon as it produces the majority of coke precursors. Reyniers et al. confirmed this assumption of three combined mechanisms thanks to experimental data [81]. They conducted coking experiments considering feedstock from methane to complex fuels like kerosene; in presence of $\mathrm{H}_{2} \mathrm{O}$ or $\mathrm{N}_{2}$. Their main conclusions were: the light species like methane and ethane produce more coke than heavier molecules; more coke is found during the pyrolysis of isoparaffin than of normal paraffin; the presence of steam relatively inhibits the coke deposit by removing it at temperatures of over $1123 \mathrm{~K}$; the solid carbon yield rises with the increase in pressure. Based on these observations, Reyniers et al. assumed that the carbon layer deposition depends on the contribution of three mechanisms. The first one is similar to the mechanism 1 described by Albright and Marek [93]. It consists in a heterogeneous catalytic mechanism which is predominant in the initial phase with a high rate of carbon deposition. Figure 3 presents a schematic view of this deposition. 


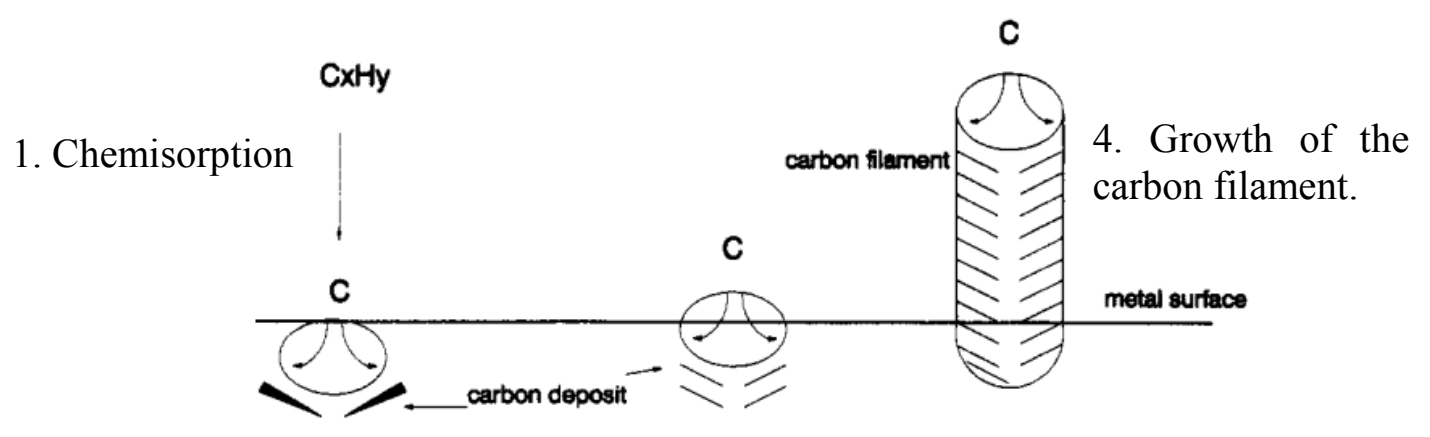

2. Decomposition and then formation of a carbonaceous 3. Formation of a carbon filament. material.

This carbon layer is a porous structure where active sites permit coke deposition via a noncatalytic mechanism. Indeed, the covering of the metal surface leads to a progressive decrease in coke 511 formation by this catalytic method. The second mechanism, described by the author as the 512 "Heterogeneous Noncatalytic Mechanism", is the predominant one. It consists of the decomposition of 513 hydrocarbons into aromatic structures and then into graphitic coke filaments. The polyaromatic layer is 514 progressively dehydrogenated by free radicals which are present in the gas phase. The number of 515 possible reactions is very large and depends on the nature of the feedstock. The last mechanism is 516 described as homogeneous and noncatalytic. It involves the formation of PAH in the gas phase. These 517 molecules agglomerate into tar droplets which generally adhere to the surface and are incorporated in 518 the coke layer. This pathway prevails for heavy liquid feedstock and at temperatures of over $1173 \mathrm{~K}$. 519 Since acetylene and PAH are the keys for the production of solid carbon, it could be of interest to take a 520 quick look at this (e.g. [94-97]). The works of Böhm et al. [94,95] could be cited as an example for the present review. They studied the growth of PAH and the formation of soot experimentally during the pyrolysis of acetylene and of benzene at high temperature and pressure. The PAH formation model that they developed was based on three reaction pathways. First, the $\mathrm{H}$-abstraction is associated with $\mathrm{C}_{2} \mathrm{H}_{2}$ addition to aromatics (e.g. acetylene addition to naphthalene forming phenanthrene and pyrene): the socalled HACA route. Then, combination reactions involve phenyl with benzene, the so-called ring-ring 
526 condensation. Finally, cyclopentadienyl is recombined (i.e. naphthalene may be formed without

527 benzene). As a conclusion, PAH growth is more dependent on the ring-ring condensation than on the

528 HACA route for short residence times. Benzene is consequently the most efficient precursor in 529 comparison with acetylene. On the contrary, for longer residence times, the benzene consumption infers 530 the dominance of acetylene as PAH precursor. The HACA route becomes essential. Equally, the optimal 531 soot production is reached when these two mechanisms work "hand in hand". Finally, the 532 cyclopentadienyl pathway is important during acetylene pyrolysis.

\section{$533 \quad 3.3$ Catalicity and coke}

As is mentioned in the previous parts, the presence of a catalyst (reactor surface or solid) can modify the course of coke formation (enhancement or limitation) $[2,33,34,44,56,78-80,84-90]$. In addition, in the presence of a catalyst, another type of coke can be produced i.e. catalytic coke. If this is generally observed as different forms, catalytic coke is mostly formed as a filamentous carbon [98,99].

538 Schematically and considering a metallic surface, the production of filamentous carbon can be 539 summarized as follows: first, the hydrocarbon is adsorbed on the surface; reactions occur and some coke 540 particles are formed; then, carbon atoms are progressively dissolved and diffuse through the metal particles; an accumulation occurs which leads to a certain tension; the metal particles are removed from

542 the surface and will act as active sites in the production of catalytic coke; a carbon filament is 543 progressively formed with metal particles at its topside. Equally, the coke could affect catalicity 544 generally by covering the reactive sites (i.e. catalytic deactivation). First, it must be mentioned that 545 several reviews have been proposed on catalytic deactivation namely due to coke deposition, 546 particularly during the last 70 s and 80 s. Precious information can be found and reference may be made 547 to the following works for complements: Rostrup-Nielsen and Trimm [100]; Butt and Billimoria [101]; 548 Trimm [102] or more recently Bartholomew [103]. Secondly, to the authors' knowledge, no works are 549 available regarding catalytic methane pyrolysis with coke production and catalyst deactivation. 550 Consequently, this review has been extended to other hydrocarbons through the presentation of the 
551 works of Guisnet and Magnoux [104-106]. In Ref.[104,105], they compared the thermal degradation of 552 n-heptane with 4 different zeolites (USHY, HMOR, HZSM5 and HERI). They evaluated the coking 553 impact on deactivation, which varies according to the nature of the zeolite. HMOR, HERI and, to a 554 lesser extent, USHY deactivates quickly contrary to HZSM5 whose deactivation is slow. The 555 deactivation is about 40 times greater for HERI, 15 times for HMOR, 3 times for USHY than for 556 HZSM5. The structure and the size of the zeolite pores on the one hand and the density of acid sites on 557 the other are responsible for this difference between zeolites. The modes of deactivation are the 558 limitation of the access (for low coking rates, particularly predominant with HSZM5) or the total 559 blockage of the access (predominant for HMOR and HERI) of the catalytic sites. In Ref.[106], Guisnet 560 and Magnoux presented some propositions in order to limit this unwanted deactivation. They isolated 3 561 points: adapting the pore structure by preferentially chose zeolites without trapping cavities; adjusting 562 the acidity of catalytic sites in order to obtain good homogeneity and finally, setting efficient operating 563 conditions in order to avoid the blockage of pores. Paweewan et al.[107] also worked on "zeolite 564 deactivation" during n-hexane degradation. They provided the main characteristics of coke particles and 565 they explained its effect on deactivation which was quite different compared with the previous case. 566 Indeed, its effect was attributed to "selective site poisoning" (i.e. the removing of the predominant 567 active sites) instead of pore blockage. Froment and coworkers[108-116] studied the deactivation of numerous catalysts (zeolites, metal) 569 with regard to coke deposition. They developed models in order to predict this phenomenon by 570 assessing the concept of site coverage and pore blockage. The particularity of this model is that time is 571 not taken into account. For example, the deactivation function $\varphi_{\mathrm{A}}$ (regarding the site coverage) for a 572 given reaction (e.g. $\mathrm{A} \rightarrow \mathrm{B}$ ) is defined as:

$$
\varphi_{\mathrm{A}}=\left(\frac{\mathrm{C}_{\mathrm{t}}-\mathrm{C}_{\mathrm{Cl}}}{\mathrm{C}_{\mathrm{t}}}\right)^{\mathrm{n}_{\mathrm{A}}}
$$
with $\mathrm{n}_{\mathrm{A}}=1$ (single site main reaction) or 2 (dual site main reaction), $\mathrm{C}_{\mathrm{t}}=$ total concentration of 575 active sites and $\mathrm{C}_{\mathrm{Cl}}=$ concentration of sites covered with coke or coke precursor. 
As a consequence, the rate $\mathrm{r}_{\mathrm{A}}$ of this reaction is modified as follows:

$$
\mathrm{r}_{\mathrm{A}}=\mathrm{r}_{\mathrm{A}}^{0} \varphi_{\mathrm{A}}
$$

with $0 \leq \varphi_{\mathrm{A}} \leq 1$ and $\mathrm{r}_{\mathrm{A}}{ }^{0}$ is the initial rate in absence of coke.

It must be noted that the deactivation of the catalyst directly affect the coke formation so that Eq.

22 is also valid for the coke rate Since these equations are not sufficient for global deactivation to be taken into account, namely regarding the probability of pore blockage, Froment et al. explained that it is necessary to develop a model using probability theory and considering the geometry of the catalysts as a network of pores. For example, in Ref.[110] they suggested a complex model of four different catalyst networks. In Ref.[112], they improved this model by taking into account the diffusion limitation. In the early 2000s, Froment published a complete work on catalyst deactivation [116]. He divided his approach according to three levels: the active sites, the catalyst particle and the reactor (referring to the previous equations used for particle level and adding equations which describe the temperature and the concentration evolutions).

Among other works from the 90s and 2000s (e.g. Ref. [48,117-122]), Beltramini et al.[117] studied coke production and the deactivation effect on a bifunctional catalyst (metallic and acidic) according to different metal contents. They highlighted the different trends between metallic and acid sites, the first one being more affected by coke production (i.e. quick deactivation) and acting as a regulator on the coke production because of its involvement in the precursors of coke. Forzatti and Lietti proposed a review on catalyst deactivation dealing with its main causes [119]: poisoning, coking or sintering phenomena. They exposed an example of catalyst deactivation considering a fluid catalytic cracking model. Finally, Reyniers et al. $[120,121]$ pointed out other important notions regarding the coke. They demonstrated its influence on several chemical reactions during the pyrolysis of several hydrocarbons: n-hexane, 2,2,4 triMe-pentane, propene, and i-butene. They showed the influence of the gas phase composition on the coking rate, notably the positive effect of olefins. The coke molecules can form carbenium ions and they act as hydride donors and, consequently, they interact and they intervene 
601 in the formation of catalytic products. For example, regarding the hexane degradation, the formation and 602 the presence of coke favors the selectivities of $\mathrm{C}_{1}$ and $\mathrm{C}_{2}$ hydrocarbons. Finally, the reaction rates can be 603 positively or negatively influenced by the coke formation according to the reaction type, the coke 604 content and the acid sites properties.

\section{Conclusions}

Pyrolysis involves a complex kinetic mechanism in the homogeneous phase whatever the initial 607 fuel composition to be considered and this becomes even more challenging when considering 608 heterogeneous reactions with a surface reactor and the formation of solid coke particles. Through the 609 literature survey presented in this work, a wide variety of experimental conditions has been presented. 610 The understanding of all the coupled phenomena which occur is not simple and numerous parameters 611 have to be considered. The nature of the inner wall drastically affects the course of thermal degradation. 612 Regarding this aspect, several elements are of importance. If the nature of the catalyst seems to be an 613 obvious factor, others should be mentioned and must be considered and in particular: the temperature, 614 the pressure, the nature of the fuel and the S/V ratio. Equally, interesting parallel parameters have been 615 assessed such as the pretreatment of the reactor or the support of the catalyst which can significantly modify the catalytic activity. Several kinetic models have been developed. Studying the interaction between gas species and active sites has become more complex by considering its potential deactivation namely by solid carbons produced during pyrolysis. The so-called coke is an unwanted product which can be of different natures, diluted in the gas phase and deposited at the surface of the reactor wall. In so doing the catalytic activity is drastically reduced which impacts the kinetics of the reaction. Several works have demonstrated the possibility of decreasing such an undesired process namely by pre-treating the surface or setting efficient conditions.

Studying such effects is incontrovertible regarding the context of regenerative cooling thanks to the endothermic degradation of fuel during hypersonic flights. If several studies are available, it is undeniable that there remains a clear lack in this domain with regard to methane and namely regarding 
626 the interaction between this fluid and its pyrolyzed product with materials of interest (i.e. composites).

627 The operating conditions should be intensively explored within the scope of limiting coke production.

\section{5. Acknowledgments}

629 This work was supported by the ESA-ESTEC, Contract 4000101998/10/NL/PA.

\section{6. References}

631 [1] Q. Sun, Y. Tang, G. Gavalas, Methane pyrolysis in a hot filament reactor, Energy Fuels. 14

[2] J. Dunkleman, L. Albright, Pyrolysis of propane in tubular flow reactors constructed of different materials, in: Ind. Lab. Pyrolyses, American Chemical Society, 1976: pp. 261-273.

635 [3] H. Huang, D. Sobel, L. Spadaccini, Endothermic heat-sink of hydrocarbon fuels for scramjet cooling, in: Endothermic Heat-Sink Hydrocarb. Fuels Scramjet Cool., 38th AIAA/ASME/SAE/ASEE Joint Propulsion Conference \& Exhibit, Indianapolis, Indiana, 2002: p.

[4] G. Liu, Y. Han, L. Wang, X. Zhang, Z. Mi, Supercritical thermal cracking of N -dodecane in presence of several initiative additives: Products distribution and kinetics, Energy Fuels. 22

[5] K. Tabayashi, S. Bauer, The early stages of pyrolysis and oxidation of methane, Combust. Flame.

644 [6] S. Anderson, Breakdown behavior of fuels for pulsed detonation engines, (2005).

645 [7] T. Bruno, M. Huber, A. Laesecke, E. Lemmon, R. Perkins, Thermochemical and thermophysical properties of JP-10, Adv. Sci. Tech. 45 (2006) 1-67. 
647 [8] S. Garner, R. Sivaramakrishnan, K. Brezinsky, The high-pressure pyrolysis of saturated and unsaturated C7 hydrocarbons, Proc. Combust. Inst. 32 (2009) 461-467.

649 [9] S. Zeppieri, S. Klotz, F. Dryer, Modeling concepts for larger carbon number alkanes: A partially reduced skeletal mechanism for n-decane oxidation and pyrolysis, Proc. Combust. Inst. 28 (2000) $1587-1595$.

[10] Y. Xing, W. Fang, W. Xie, Y. Guo, R. Lin, Thermal cracking of JP-10 under pressure, Ind. Eng. Chem. Res. 47 (2008) 10034-10040.

654 [11] J. Chakraborty, D. Kunzru, High pressure pyrolysis of n-heptane, J. Anal. Appl. Pyrolysis. 86 (2009) 44-52.

[12] J. Dahl, V. Barocas, D. Clough, A. Weimer, Intrinsic kinetics for rapid decomposition of methane in an aerosol flow reactor, Int. J. Hydrog. Energy. 27 (2002) 377-386.

[13] M. Khan, B. Crynes, Survey of recent methane pyrolysis literature, Ind. Eng. Chem. Res. 62 (1970) 54-59.

[14] F. Billaud, F. Baronnet, E. Freund, C. Busson, J. Weill, Thermal decomposition of methane: bibliographic study and proposal of a mechanism, Rev. I. Fr. Pet. 44 (1989) 813-823.

[15] G. Fau, N. Gascoin, P. Gillard, J. Steelant, Methane Pyrolysis: literature survey and comparisons of available data for use in numerical simulations, J. Anal. Appl. Pyrolysis. 104 (2013) 1-9.

664 [16] A. Gordon, Pyrolysis of methane flowing through a porcelain tube in the region $1000^{\circ}$, J. Am. Chem. Soc. 70 (1948) 395-401.

[17] J. Weill, P. Broutin, F. Billaud, C. Guéret, Coke Formation During Hydrocarbons Pyrolysis. Part 667 One: Steam Cracking, Oil Gas Sci. Technol. 47 (1992) 537-549. 
668 [18] H. Cai, A. Krzywicki, M.C. Oballa, Coke formation in steam crackers for ethylene production, Chem. Eng. Process. 41 (2002) 199-214.

670

671

672

673

674

675

676

677

678

679

680

681

682

683

684

685

686

687

[19] C. Yue, A. Watkinson, J. Lucas, K. Chung, Incipient coke formation during heating of heavy hydrocarbons, Fuel. 83 (2004) 1651-1658.

[20] N. Gascoin, P. Gillard, S. Bernard, M. Bouchez, Characterisation of coking activity during supercritical hydrocarbon pyrolysis, Fuel Process. Technol. 89 (2008) 1416-1428.

[21] N. Gascoin, Coking Activity During Supercritical Hydrocarbon Pyrolysis, Hydrocarb. World. 5 (2010) 17-20.

[22] N. Gascoin, G. Abraham, P. Gillard, Thermal and hydraulic effects of coke deposit in hydrocarbon pyrolysis process., 17th AIAA Int. Sp. Planes Hypersonic Syst. Technol. Conf. 2205 (2011).

[23] M. Bajus, V. Vesel, P. Leclercq, J. Rijks, Steam Cracking of Hydrocarbons. 1. Pyrolysis of Heptane, Ind. Eng. Chem. Res. 18 (1979) 30-37.

[24] G. Fau, N. Gascoin, P. Gillard, Fuel Pyrolysis through Porous Media : Coke Formation and Coupled effect on Permeability, 17th AIAA Int. Sp. Planes Hypersonic Syst. Technol. Conf. 2206 (2011).

[25] N. Gascoin, G. Abraham, P. Gillard, Thermal and Hydraulic Effects of Coke Deposit in Hydrocarbon Pyrolysis Process, J. Thermophys Heat Transf. 26 (n.d.) 57-65.

[26] G. Fau, N. Gascoin, P. Gillard, M. Bouchez, Fuel Pyrolysis through Porous Media: Coke Formation and Coupled effect on Permeability, J. Anal. Appl. Pyrolysis. 95 (2012) 180-188. 
[27] M. Bouchez, E. Daniau, N. Visez, O. Herbinet, R. Fournet, P. Marquaire, Hydrocarbons Heterogeneous Pyrolysis: Experiments and Modeling for Scramjet Thermal Management, 15th AIAA Int. Sp. Planes Hypersonic Syst. Technol. Conf. (2009).

[28] K. Davis, W. Cerven, W. Solomon, The use of methane as a fuel for hypersonic propulsion, in: Use Methane as a Fuel Hypersonic Propuls., 31st AIAA/ASME/SAE/ASEE Joint Propulsion Conference and Exhibit, San Diego, California, 1995: p. 2769.

[29] C. Hurd, F. Pilgrim, The Pyrolysis of Hydrocarbons. Further Studies on the Butanes, J. Am. Chem. Soc. 55 (1933) 4902-4907.

[30] W. Slater, The influence of different surfaces on the decomposition of methane, J. Chem. Soc. Trans. 109 (1916) 160-164.

[31] C. Hurd, L. Eilers, Pyrolysis Studies-Isobutylene, Diisobutylene, Ethylene, Propylene, and 2Pentene, Ind. Eng. Chem. Res. 26 (1934) 776-780.

[32] B. Crynes, L. Albright, Pyrolysis of propane in tubular flow reactors. Kinetics and surface effects, Ind. Eng. Chem. Res. 8 (1969) 25-31.

[33] M. Ghaly, B. Crynes, Reactor Surface Effects During Propylene Pyrolysis, in: Ind. Lab. Pyrolyses, American Chemical Society, 1976: pp. 218-240.

[34] J. Dunkleman, L. Albright, Surface Effects During Pyrolysis of Ethane in Tubular Flow Reactors, in: Ind. Lab. Pyrolyses, American Chemical Society, 1976: pp. 241-260.

[35] N. Gascoin, P. Gillard, S. Bernard, E. Daniau, M. Bouchez, Pyrolysis of supercritical endothermic fuel: Evaluation for active cooling instrumentation, Int. J. Chem. React. Eng. 6 (2008). 
709 [36] N. Gascoin, G. Abraham, P. Gillard, Synthetic and jet fuels pyrolysis for cooling and combustion applications, J. Anal. Appl. Pyrolysis. 89 (2010) 294-306.

711 [37] G. Abraham, Etude et développement d'une méthode d'analyse par spectroscopie infrarouge appliquée à la pyrolyse d'hydrocarbures en conditions supercritiques et transitoires, Ph.D. Thesis.

714 [38] J. Li, J. Zou, X. Zhang, W. Guo, Z. Mi, Catalytic cracking of endothermic fuels in coated tube

[39] H. Zhao, F. Meng, W. Guo, J. Zou, X. Zhang, Pd/HZSM-5 coating catalyst for supercritical cracking of endothermic fuel, J. Fuel Chem. Technol. 36 (2008) 462-467.

718 [40] F. Meng, G. Liu, S. Qu, L. Wang, X. Zhang, Z. Mi, Catalytic cracking and coking of supercritical n-dodecane in microchannel coated with HZSM-5 zeolites, Ind. Eng. Chem. Res. 49 (2010) 8977-8983.

[41] Y. Xing, D. Li, W. Xie, W. Fang, Y. Guo, R. Lin, Catalytic cracking of tricyclo [5.2.1.02.6] decane over HZSM-5 molecular sieves, Fuel. 89 (2010) 1422-1428.

[42] G. Liu, G. Zhao, F. Meng, S. Qu, L. Wang, X. Zhang, Catalytic Cracking of Supercritical nDodecane over Wall-Coated HZSM-5 Zeolites with Micro-and Nanocrystal Sizes, Energy Fuels. 26 (2012) 1220-1229.

[43] T. Fang, C. Yeh, Catalytic pyrolysis of methane, J. Chin. Chem. Soc. 29 (1981) 265-273.

[44] G.P. VanDerZwet, P. Hendriks, R. VanSanten, Pyrolysis of methane and the role of surface area, Catal. Today. 4 (1989) 365-369. 
[45] M. Wolf, O. Deutschmann, F. Behrendt, J. Warnatz, Kinetic model of an oxygen-free methane conversion on a platinum catalyst, Catal. Lett. 61 (1999) 15-25.

[46] M. Belgued, A. Amariglio, P. Paréja, Oxygen-Free Conversion of Methane to Higher Alkanes through an Isothermal Two-Step Reaction on Platinum (EUROPT-1) I. Chemisorption of Methane, J. Catal. 166 (1996) 118-120.

[47] S. Bao, G. Liu, X. Zhang, L. Wang, Z. Mi, New method of catalytic cracking of hydrocarbon fuels using a highly dispersed nano-HZSM-5 catalyst, Ind. Eng. Chem. Res. 49 (2010) 39723975.

[48] X. Xian, G. Liu, Z. Zhang, L. Wang, Z. Mi, Catalytic cracking of n-dodecane over HZSM-5 zeolite under supercritical conditions: Experiments and kinetics, Chem. Eng. Sci. 65 (2010) $5588-5604$.

[49] Z. Dardas, G. Murat, Y. Ma, W. Moser, A Kinetic Study of n-Heptane Catalytic Cracking over a Commercial Y-Type Zeolite under Supercritical and Subcritical Conditions, J. Catal. 162 (1996) $327-338$.

[50] N. Muradov, Catalysis of methane decomposition over elemental carbon, Catal. Commun. 2 (2001) 89-94.

[51] N. Muradov, CO2-free production of hydrogen by catalytic pyrolysis of hydrocarbon fuels for transportation, Energy Fuels. 12 (1998) 41-48.

[52] K. Lee, G. Han, K. Yoon, B. Lee, Thermocatalytic hydrogen production from the methane in a fluidized bed with activated carbon catalyst, Catal. Today. 93-95 (2004) 81-86.

[53] J. Pinilla, I. Suelves, M. Lázaro, R. Moliner, Kinetic study of the thermal decomposition of methane using carbonaceous catalysts, Chem. Eng. J. 138 (2008) 301-306. 
751 [54] Z. Bai, H. Chen, B. Li, W. Li, Catalytic decomposition of methane over activated carbon, J. Anal. Appl. Pyrolysis. 73 (2005) 335-341.

753 [55] R. Moliner, I. Suelves, M. Lázaro, O. Moreno, Thermocatalytic decomposition of methane over activated carbons: influence of textural properties and surface chemistry, Int. J. Hydrog. Energy.

[56] P. Ferreira-Aparicio, I. Rodriguez-Ramos, A. Guerrero-Ruiz, Methane interaction with silica and

[57] S. Takenaka, H. Ogihara, I. Yamanaka, K. Otsuka, Decomposition of methane over supported-Ni catalysts: effects of the supports on the catalytic lifetime, Appl. Catal. A-Gen. 217 (2001) 101110.

[58] S. Zein, A. Mohamed, P. Sai, Kinetic studies on catalytic decomposition of methane to hydrogen and carbon over Ni/TiO2 catalyst, Ind. Eng. Chem. Res. 43 (2004) 4864-4870.

[59] J. Zadeh, K. Smith, Kinetics of CH4 decomposition on supported cobalt catalysts, J. Catal. 176 (1998) 115-124.

[60] Y. Xu, L. Lin, Recent advances in methane dehydro-aromatization over transition metal ionmodified zeolite catalysts under non-oxidative conditions, Appl. Catal. A-Gen. 188 (1999) 53-67.

767 [61] F. Solymosi, J. Cserenyi, A. Szöke, T. Bansagi, A. Oszko, Aromatization of methane over supported and unsupported Mo-based catalysts, J. Catal. 165 (1997) 150-161.

[62] F. Solymosi, A. Erdöhelyi, A. Szöke, Dehydrogenation of methane on supported molybdenum oxides. Formation of benzene from methane, Catal. Lett. 32 (1995) 43-53. 
771 [63] F. Solymosi, A. Szöke, J. Cserenyi, Conversion of methane to benzene over Mo2C and Mo2C/ZSM-5 catalysts, Catal. Lett. 39 (1996) 157-161.

773 [64] J. Lunsford, Catalytic conversion of methane to more useful chemicals and fuels: a challenge for 774 the 21st century, Catal. Today. 63 (2000) 165-174.

[65] A. Holmen, Direct conversion of methane to fuels and chemicals, Catal. Today. 142 (2009) 2-8.

[66] N. Shah, D. Panjala, G. Huffman, Hydrogen production via catalytic decomposition of methane, Energy \& Fuels. 15 (2001) 1528-1534.

[67] I. González, J. De Jesus, C. De Navarro, M. Garcia, Effect of Cu on Ni nanoparticles used for the generation of carbon nanotubes by catalytic cracking of methane, Catal. Today. 149 (2010) 352357.

[68] A. Amin, E. Croiset, W. Epling, Review of methane catalytic cracking for hydrogen production, 782

[69] S. Ahmed, A. Aitani, F. Rahman, A. Al-Dawood, F. Al-Muhaish, Decomposition of hydrocarbons to hydrogen and carbon, Appl. Catal. A-Gen. 359 (2009) 1-24.

[70] H. Abbas, W. Wan Daud, Hydrogen production by methane decomposition: a review, Int. J. Hydrog. Energy. 35 (2010) 1160-1190.

[71] L. Albright, C. McConnell, K. Welther, Types of coke formed during the pyrolysis of light hydrocarbons, in: Therm. Hydrocarb. Chem., Purdue Univ., West Lafayette, IN, 1979: pp. 175191.

[72] E. Fitzer, K. Kochling, H. Boehm, H. Marsh, Recommended terminology for the description of carbon as a solid, Pure Appl. Chem. 67 (1995) 473-506. 
792 [73] T. Edwards, S. Zabarnick, Supercritical fuel deposition mechanisms, Ind. Eng. Chem. Res. 32 (1993) 3117-3122.

794 [74] W. Xie, W. Fang, D. Li, Y. Xing, Y. Guo, R. Lin, Coking of model hydrocarbon fuels under supercritical condition, Energy Fuels. 23 (2009) 2997-3001.

[75] A. Baiker, Supercritical fluids in heterogeneous catalysis, Chem. Rev. 99 (1999) 453-474.

[76] E. Blekkan, R. Myrstad, O. Olsvik, O. Rokstad, Characterization of tars and coke formed during the pyrolysis of methane in a tubular reactor, Carbon N. Y. 30 (1992) 665-673.

[77] C. Guéret, F. Billaud, B. Fixari, P. Le Perchec, Thermal coupling of methane, experimental investigations on coke deposits, Carbon N. Y. 33 (1995) 159-170.

[78] L. Albright, J. Marek, Coke formation during pyrolysis: Roles of residence time, reactor geometry, and time of operation, Ind. Eng. Chem. Res. 27 (1988) 743-751.

[79] O. Altin, S. Eser, Characterization of carbon deposits from jet fuel on Inconel 600 and Inconel X surfaces, Ind. Eng. Chem. Res. 39 (2000) 642-645.

[80] O. Altin, E. Semih, Analysis of solid deposits from thermal stressing of a JP-8 fuel on different tube surfaces in a flow reactor, Ind. Eng. Chem. Res. 40 (2001) 596-603.

[81] G. Reyniers, G. Froment, F. Kopinke, G. Zimmermann, Coke formation in the thermal cracking of hydrocarbons. 4. Modeling of coke formation in naphtha cracking, Ind. Eng. Chem. Res. 33

[82] P. Lucas, A. Marchand, Pyrolytic carbon deposition from methane: an analytical approach to the chemical process, Carbon N. Y. 28 (1990) 207-219. (1994) 2584-2590.

[83] A. Oberlin, Pyrocarbons, Carbon N. Y. 40 (2002) 7-24. 
813 [84] O. Altin, S. Eser, Analysis of carboneceous deposits from thermal stressing of a JP-8 fuel on 814 superalloy foils in a flow reactor, Ind. Eng. Chem. Res. 40 (2001) 589-595.

815 [85] A. Radwan, T. Kyotani, A. Tomita, Characterization of coke deposited from cracking of benzene 816 over USY zeolite catalyst, Appl. Catal. A-Gen. 192 (2000) 43-50.

817 [86] A. Shamsi, J. Baltrus, J. Spivey, Characterization of coke deposited on Pt/alumina catalyst during reforming of liquid hydrocarbons, Appl. Catal. A-Gen. 293 (2005) 145-152.

819 [87] W. Zhiyuan, X. Hong, L. Xiaojian, H. Feng, Z. Jianxin, Effect of Potassium Acetate on Coke Growth during Light Naphtha Thermal Cracking, Ind. Eng. Chem. Res. 50 (2011) 10292-10297.

[88] E. Furimsky, Characterization of cokes from fluid/flexi-coking of heavy feeds, Fuel Process. Technol. 67 (2000) 205-230.

[89] H. Schobert, C. Eser, C. Song, P. Hatcher, A. Boehman, M. Coleman, Advanced thermally stable 824 jet fuels, 1996.

[90] M. Guisnet, P. Magnoux, Organic chemistry of coke formation, Appl. Catal. A-Gen. 212 (2001) 83-96.

[91] W. Benzinger, A. Becker, K. Hüttinger, Chemistry and kinetics of chemical vapour deposition of pyrocarbon: I. Fundamentals of kinetics and chemical reaction engineering, Carbon N. Y. 34 (1996) 957-966.

[92] A. Becker, K. Hüttinger, Chemistry and kinetics of chemical vapor deposition of pyrocarbon-IV pyrocarbon deposition from methane in the low temperature regime, Carbon N. Y. 36 (1998) $213-224$. 
833 [93] L. Albright, J. Marek, Mechanistic model for formation of coke in pyrolysis units producing $834 \quad$ ethylene, Ind. Eng. Chem. Res. 27 (1988) 755-759.

835 [94] H. Böhm, H. Jander, D. Tanke, PAH growth and soot formation in the pyrolysis of acetylene and 836

[95] H. Böhm, H. Jander, PAH formation in acetylene-benzene pyrolysis, Phys. Chem. Chem. Phys. 1 (1999) 3775-3781.

[96] P. Vlasov, J. Warnatz, Detailed kinetic modeling of soot formation in hydrocarbon pyrolysis behind shock waves, Proc. Combust. Inst. 29 (2002) 2335-2341.

[98] R. Terry, K. Baker, Coking problems associated with hydrocarbon conversion processes, Prepr. Pap. Am. Chem. Soc. Div. Fuel Chem. 41 (1996) 521-524.

[99] R. Baker, M. Barber, P. Harris, R. Waite, Nucleation and growth of carbon deposits from the nickel catalyzed decomposition of acetylene, J. Catal. 62 (1972) 51-62.

849 [100] J. Rostrup-Nielsen, D. Trimm, Mechanisms of carbon formation on nickel-containing catalysts, J. Catal. 48 (1977) 155-165.

851 [101] J. Butt, R. Billimoria, Catalyst Deactivation, in: Chem. React. Eng. Rev., American Chemical Society, 1978: pp. 288-322.

[102] D. Trimm, Catalyst design for reduced coking (review), Appl. Catal. 5 (1983) 263-290. 
854 [103] C. Bartholomew, Mechanisms of catalyst deactivation, Appl. Catal. A-Gen. 212 (2001) 17-60.

855 [104] M. Guisnet, P. Magnoux, Coking and deactivation of zeolites: Influence of the Pore Structure, 856 Appl. Catal. 54 (1989) 1-27.

857

858

859

860

861

862

863

864

865

866

867

868

869

870

871

872

873

874

[105] P. Magnoux, M. Guisnet, Coking, aging, and regeneration of zeolites: X-nature of coke formed on H-erionite during n-heptane cracking, mode of deactivation, Zeolites. 9 (1989) 329-335.

[106] M. Guisnet, P. Magnoux, Deactivation by coking of zeolite catalysts. Prevention of deactivation. Optimal conditions for regeneration, Catal. Today. 36 (1997) 477-483.

[107] B. Paweewan, P. Barrie, L. Gladden, Coking and deactivation during n-hexane cracking in ultrastable zeolite Y, Appl. Catal. A-Gen. 185 (1999) 259-268.

[108] R. De Pauw, G. Froment, Deactivation of a platinum reforming catalyst in a tubular reactor, Chem. Eng. Sci. 30 (1975) 789-801.

[109] J. Beeckmann, G. Froment, P. L, Deactivation of porous catalysts by coke formation, Chem. Ing. Tech. 12 (1978) 960-961.

[110] J. Beeckman, G. Froment, Catalyst deactivation by active site coverage and pore blockage, Ind. Eng. Chem. Fundam. 18 (1979) 245-256.

[111] J. Beeckman, G. Froment, Catalyst deactivation by site coverage and pore blockage: Finite rate of growth of the carbonaceous deposit, Chem. Eng. Sci. 35 (1980) 805-815.

[112] J. Beeckman, G. Froment, Deactivation of catalysts by coke formation in the presence of internal diffusional limitation, Ind. Eng. Chem. Fundam. 21 (1982) 243-250.

[113] G. Marin, J. Beeckman, G. Froment, Rigorous kinetic models for catalyst deactivation by coke deposition: Application to butene dehydrogenation, J. Catal. 426 (1986) 416-426. 
875 [114] I. Nam, G. Froment, Catalyst deactivation by site coverage through multi-site reaction

876 mechanisms, J. Catal. 108 (1987) 271-282.

877 [115] G. Froment, J. Meyer, E. Derouane, Deactivation of zeolite catalysts by coke formation, J. Catal. $878 \quad 124(1990) 391-400$.

879 [116] G. Froment, Modeling of catalyst deactivation, Appl. Catal. A-Gen. 212 (2001) 117-128.

880 [117] J. Beltramini, T. Wessel, D. Ravindra, Kinetics of deactivation of bifunctional Pt/Al2O3-Cl $881 \quad$ catalysts by coking, AIChE J. 37 (1991) 845-854.

882 [118] W. Groten, B. Wojciechowski, B. Hunter, On the relationship between coke formation chemistry 883 and catalyst deactivation, J. Catal. 138 (1992) 343-350.

884 [119] P. Forzatti, L. Lietti, Catalyst deactivation, Catal. Today. 52 (1999) 165-181.

885 [120] M. Reyniers, H. Beirnaert, G. Marin, Influence of coke formation on the conversion of 886 hydrocarbons I. Alkanes on a USY-zeolite, Appl. Catal. A-Gen. 202 (2000) 49-63.

887 [121] M. Reyniers, Y. Tang, G. Marin, Influence of coke formation on the conversion of hydrocarbons: 888 II. i-Butene on HY-zeolites, Appl. Catal. A-Gen. 202 (2000) 65-80.

889 [122] A. Mohamadalizadeh, J. Towfighi, R. Karimzadeh, Modeling of catalytic coke formation in 890 thermal cracking reactors, J. Anal. Appl. Pyrolysis. 82 (2008) 134-139. 